\title{
BMJ Open Lifetime, 5-year and past-year prevalence of homelessness in Europe: a cross-national survey in eight European nations
}

Owen Taylor (D) , ${ }^{1}$ Sandrine Loubiere (D) ,1,2 Aurelie Tinland, ${ }^{1,2}$ Maria Vargas-Moniz, ${ }^{3}$ Freek Spinnewijn, ${ }^{4}$ Rachel Manning, ${ }^{5}$ Marta Gaboardi, ${ }^{6}$ Judith R L M Wolf, ${ }^{7}$ Ana Bokszczanin, ${ }^{8}$ Roberto Bernad, ${ }^{9}$ Hakan Kallmen, ${ }^{10}$ Paul Toro, ${ }^{11}$ Jose Ornelas, ${ }^{3}$ Pascal Auquier, ${ }^{1,2}$ HOME_EU Consortium Study Group

To cite: Taylor 0, Loubiere S, Tinland A, et al. Lifetime, 5year and past-year prevalence of homelessness in Europe: a cross-national survey in eight European nations. BMJ Open 2019;9:e033237. doi:10.1136/ bmjopen-2019-033237

- Prepublication history and additional material for this paper are available online. To view these files, please visit the journal online (http://dx.doi. org/10.1136/bmjopen-2019033237).

Received 26 July 2019 Revised 07 November 2019 Accepted 11 November 2019

Check for updates

(C) Author(s) (or their employer(s)) 2019. Re-use permitted under CC BY-NC. No commercial re-use. See rights and permissions. Published by BMJ.

For numbered affiliations see end of article.

Correspondence to

Dr Sandrine Loubiere;

sandrine.loubiere@univ-amu.fr

\section{ABSTRACT}

Objectives To examine the lifetime, 5-year and past-year prevalence of homelessness among European citizens in eight European nations.

Design A nationally representative telephone survey using trained bilingual interviewers and computer-assisted telephone interview software.

Setting The study was conducted in France, Ireland, Italy, the Netherlands, Poland, Portugal, Spain and Sweden. Participants European adult citizens, selected from optin panels from March to December 2017. Total desired sample size was 5600 , with 700 per country. Expected response rates of approximately $30 \%$ led to initial sample sizes of 2500 per country.

Main outcome measures History of homelessness was assessed for lifetime, past 5 years and past year. Sociodemographic data were collected to assess correlates of homelessness prevalence using generalised linear models for clustered and weighted samples.

Results Response rates ranged from $30.4 \%$ to $33.5 \%$ $(n=5631)$. Homelessness prevalence was $4.96 \%$ for lifetime (95\% Cl $4.39 \%$ to $5.59 \%), 1.92 \%$ in the past 5 years $(95 \% \mathrm{Cl} 1.57 \%$ to $2.33 \%)$ and $0.71 \%$ for the past year $(95 \% \mathrm{Cl} 0.51 \%$ to $0.98 \%)$ and varied significantly between countries (pairwise comparison difference test, $p<0.0001)$. Time spent homeless ranged between less than a week (21\%) and more than a year (18\%), with high contrasts between countries $(p<0.0001)$. Male gender, age 45-54, lower secondary education, single status, unemployment and an urban environment were all independently strongly associated with lifetime homelessness (all $\mathrm{OR}>1.5$ ).

Conclusions The prevalence of homelessness among the surveyed nations is significantly higher than might be expected from point-in-time and homeless service use statistics. There was substantial variation in estimated prevalence across the eight nations. Coupled with the well-established health impacts of homelessness, medical professionals need to be aware of the increased health risks of those with experience of homelessness. These findings support policies aiming to improve health services for people exposed to homelessness.

\section{Strengths and limitations of this study}

- Current prevalence of homelessness in Europe is unknown, cross-national and comparative data are scarce and measures of homelessness vary widely across Europe.

- The current study involves a large sample of European citizens from eight nations with widely varying health and social systems.

- The study used a relevant probability-weighted approach to ensure the representativeness of the sample, and included an extremely low rate of missing data.

- The survey was not able to build a pattern of cumulative periods of homelessness or to investigate how periods of homelessness related to unemployment or other forms of social stress.

\section{INTRODUCTION}

Recent decades have seen a marked rise in homelessness across Europe. ${ }^{1}$ Although there continues to be a lack of comparable information, ${ }^{2}$ expert estimates from 2009 suggested that, each year, about 4.1 million people in the European Union were unsheltered, or in emergency or temporary accommodation. ${ }^{3}$ This growth in the number of people experiencing homelessness has encompassed an increased number of women, youth, families and migrants. ${ }^{1}$ As an extreme expression of both poverty and inequality, homelessness has a significant impact on the health and well-being of individuals who experience homelessness. ${ }^{4}$ In addition, any period of homelessness has been shown to be an indicator of greater risk of various mental and physical health problems, including the physical and mental stress of homelessness leading to the earlier experience of age-related health problems than among the general 
population. ${ }^{5}$ The prevalence of homelessness within a country serves as a good indicator for the numbers of people exposed to high levels of poverty, social dislocation and exclusion, and consequent greater health risks. This compounds the importance of improved quantitative homelessness prevalence data to formulate better health and social policy across Europe and other regions.

Although policies vary greatly between countries, the rise in homelessness throughout Europe has coincided with a general reduction in social spending, accompanied by policies aimed at reducing the visibility of homelessness in public spaces, including hostile urban design. ${ }^{67}$ On the other hand, many European governments have expressed commitments to ending long-term homelessness. Given this situation, accurate data on homelessness in Europe are sorely needed. Definitions and methods of counting homelessness vary widely, which has led to past difficulties in comparing figures across countries. ${ }^{18}$ Prevalence studies take a different approach to existing measures, aiming to assess the experience of homelessness across the broader population over longer time periods. There are a variety of homelessness prevalence studies in the USA, ${ }^{9} 10$ and to date one comparative study examining prevalence in the USA and in four European countries, although data collection for this study was dispersed and is over 10 years old. ${ }^{11}$ Comprehensive and recent prevalence data for Europe are still lacking, with the current reported increase in homelessness across Europe based on official counts of rough sleepers (pointin-time (PIT) counts) and homeless service users. Both of these measures are certain to underestimate the prevalence of homelessness among the broader population, and to oversample people who experience the most visible forms of homelessness. ${ }^{9}$

In this study, part of a broader European project on long-term homelessness, ${ }^{12}$ our aims were: (1) to assess the lifetime, 5-year and past-year prevalence of homelessness among the general population, based on large samples drawn to be nationally representative; (2) to compare prevalence estimates across countries and (3) to assess their correlates.

\section{METHODS}

\section{Study design and sample}

A quota telephone survey using landlines and mobile phones was conducted between March and December 2017. The survey was conducted in eight European countries, namely France, Ireland, Italy, the Netherlands, Poland, Portugal, Spain and Sweden. To determine an adequate sample size, we consulted Barlett $e t a l$ s statistical tables that present the different sizes of a simple random sample according to the target population's size, the desired level of precision and heterogeneity or variability within the target population (default $=0.5$ ). In the case of large target populations $(n>100000)$ and for an accuracy of $\pm 5 \%$, the sample size is recommended to be a minimum of 400 individuals actually surveyed. ${ }^{13}$ Given possible drop-outs during the interviews, we extended the sample size to a total of 700 individuals surveyed in each country, representing a total of 5600 European citizens across the eight countries. Respondents were randomly selected from opt-in panels to be representative of the general population of each participating country. Based on European telephone survey response rates and our survey topic of homelessness, we expected response rates of approximately $30 \%$. Therefore, initial sample sizes of 2500 per country were taken. The survey questionnaire was translated into different European languages using standardised best practice ${ }^{14}$ and interviews conducted using computer assisted telephone interview software. Respondents (18 years and older) were informed of the purpose of the study, intended data use and were assured of anonymity. Respondents were free to decline to participate. Full details of the survey protocol are available. ${ }^{15}$

\section{Measures}

The measures for this study were the prevalence rates for lifetime, 5-year and past-year literal homelessness; total time spent homeless and respondent sociodemographic data. First, respondents were informed that, in this study, we defined homelessness as 'sleeping in the street, in a car or living in an emergency or temporary shelter', encompassing 1 and 2 from the European Typology of Homelessness and Housing Exclusion (namely the most visible forms of literal homelessness). ${ }^{16}$ The respondents were then posed the question, 'have you ever been homeless?' Our questions also asked respondents if reported homelessness was one of five response options: ' in the past 12 months', '1-2 years ago', '3-4 years ago', '4-5 years ago', and 'more than 5 years ago'. Respondents who reported 'Do not know' or 'Refusal to answer' were kept in the descriptive analysis. Respondents' answers were grouped to provide data for past-year, 5-year and lifetime prevalence estimates.

Respondents who reported homelessness were asked a follow-up question to determine the time spent homeless: 'How much time in total have you been homeless over your life? Would you say 'less than a week', 'less than a month', 'less than a year', 'less than 2 years', 'less than 4 years', or 'more than 4 years'?'. Respondents' answers were grouped to provide data for homeless durations of 'less than a week', 'less than a month but more than a week',' less than a year but more than a month' and 'more than a year'.

Data on sociodemographic characteristics of respondents were collected, namely: gender, age, educational level, professional status, annual household income, marital status and living area as self-reported by respondents (with the question 'would you say that you live in' followed by the options of urban, semiurban or rural areas). 


\section{Data analysis}

The distribution of age, gender and education was assessed in each national sample to gauge its representativeness of respective general populations. Since discrepancies were found between the distribution of those variables and the 2017 census data obtained through the World Bank ${ }^{17}$ and Eurostat, ${ }^{18}$ weights were applied. The 2017 census data on distribution of sex, education and age variables were obtained through the World Bank and Eurostat. Our weight variable was based on the known distribution of the entire population according to age, sex and education. In our case, the weight variable was poststratified to match the entire population in each country to ensure that calculated estimates were representative of the surveyed European populations. Each participant in the survey dataset was, therefore, assigned a unique weight.

Between September 2017 and December 2017, a control of the quality of the database was undertaken and percentages of missing data for each variable were calculated. Full descriptive analyses were conducted of all variables from the database; specifically the distribution of gender, age and education was assessed in each national sample to address representativeness. A weighted sample, as described above, was built in January 2018. Missing data for the overall study were less than $0.5 \%$ and missing variables were not included in the analysis.

Prevalence estimates were described as proportions with $95 \%$ Confidence Intervals (CIs). Generalised linear models (GLMs) for clustered (on country) and weighted samples were used to test the significance of the differences between individuals with experience of homelessness and their counterparts on sociodemographic characteristics. Bivariate analyses were conducted on lifetime and 5-year prevalence outcomes. Post hoc multiple comparisons using analysis of variance significant difference tests were conducted on unweighted subsamples to address pairwise comparisons between countries. Multivariate analyses were conducted with sociodemographic variables X country (ie, clusters) interactions tested to address whether the effect of the respondents' characteristics generalised among the eight countries. If statistically significant, these interactions implied different patterns for countries. Odds Ratios (ORs) with 95\% CIs and p values were reported. Multivariable analyses included only variables that were found to be significantly different $(\mathrm{p}<0.01)$ between groups (with and without homelessness experience) in the bivariate analyses. The analysis was conducted with the R Foundation for Statistical Computing, V.3.4.0, ${ }^{19}$ using 'Survey' and 'FactoMineR' packages.

\section{Public involvement}

The public was not involved in the design, conduct or reporting of the research.
RESULTS

\section{Sample description}

Response rates were slightly better than expected, and ranged from $30.4 \%$ to $33.5 \%$, resulting in a total number of 5631 respondents producing 5295 valid questionnaires. The majority of respondents were women $(52 \%$ for the overall sample), except in the Netherlands $(48.1 \%)$ and France $(47.7 \%$ ) (table 1 ). A majority of respondents were either married or in a civil union, most notably in Poland (71\%) and Ireland (69\%). At least $48 \%$ completed higher education. Respondents were mainly employed either full time or part time, except in Ireland (48\%).

\section{Prevalence of homelessness}

Overall pooled lifetime prevalence of homelessness as defined in this study was $4.96 \%$ (95\% CI $4.39 \%$ to $5.59 \%$ ), although there was significant variation between countries (see table 2). Spain reported the highest lifetime prevalence with $12.6 \%$, and Ireland had the lowest at $1.7 \%$. Five-year prevalence was $1.92 \%$ (95\% CI $1.57 \%$ to $2.33 \%$ ) across all countries, with the highest rates again in Spain at $6.2 \%$ and the lowest in Ireland at $0.4 \%$. Pastyear prevalence was reported at $0.71 \%(95 \%$ CI $0.51 \%$ to $0.98 \%$ ) across surveyed countries, with highs of $2.0 \%$ in Spain, to no reported past-year homelessness in Portugal. Pairwise comparisons are reported in online supplementary material e-Table 1.

\section{Time spent homeless}

The high rates of refusals or 'don't know' responses for Ireland (42\%) and Portugal (36\%) for this survey question are of concern (see table 3 ). With this in mind, nearly half of respondents $(48 \%)$ reported being homeless for less than a month, except in the Netherlands and Sweden with, respectively, $65 \%$ and $71 \%$ of respondents stating a longer duration. In the French sample, a very small proportion of respondents $(8 \%)$ experienced homelessness lasting less than a week or more than a year $(4 \%)$, with a vast majority $(81 \%)$ who reported experiencing homelessness between a week and a month. Although Spain reported the highest homelessness prevalence in Europe, respondents reported a shorter average total time spent homeless, with $56 \%$ reporting a total duration of less than a month, and only $10 \%$ more than a year. Pairwise comparisons are reported in online supplementary material e-Table 1.

\section{Association between prevalence and sociodemographics}

Table 4 shows the results of bivariate and multivariate GLMs on lifetime and 5-year prevalence outcomes (a small sample size for past-year prevalence prevented comparison with sociodemographic data). Male respondents were 2.6 times as likely to report lifetime homelessness; those with lower educational attainment, respondents who were not married, those with current non-working status and those living in an urban area were nearly two times as likely to report lifetime homelessness. Respondents having relatives, friends or acquaintances who had 


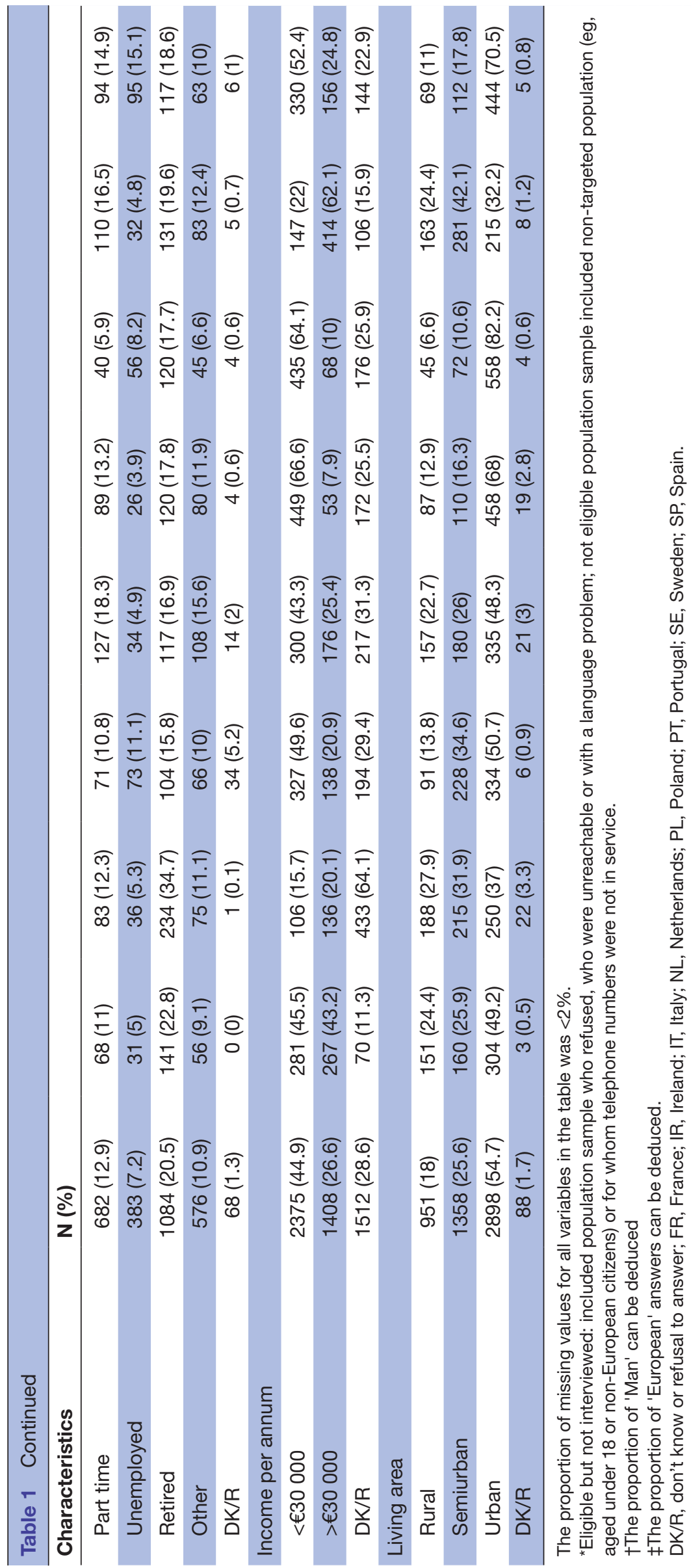




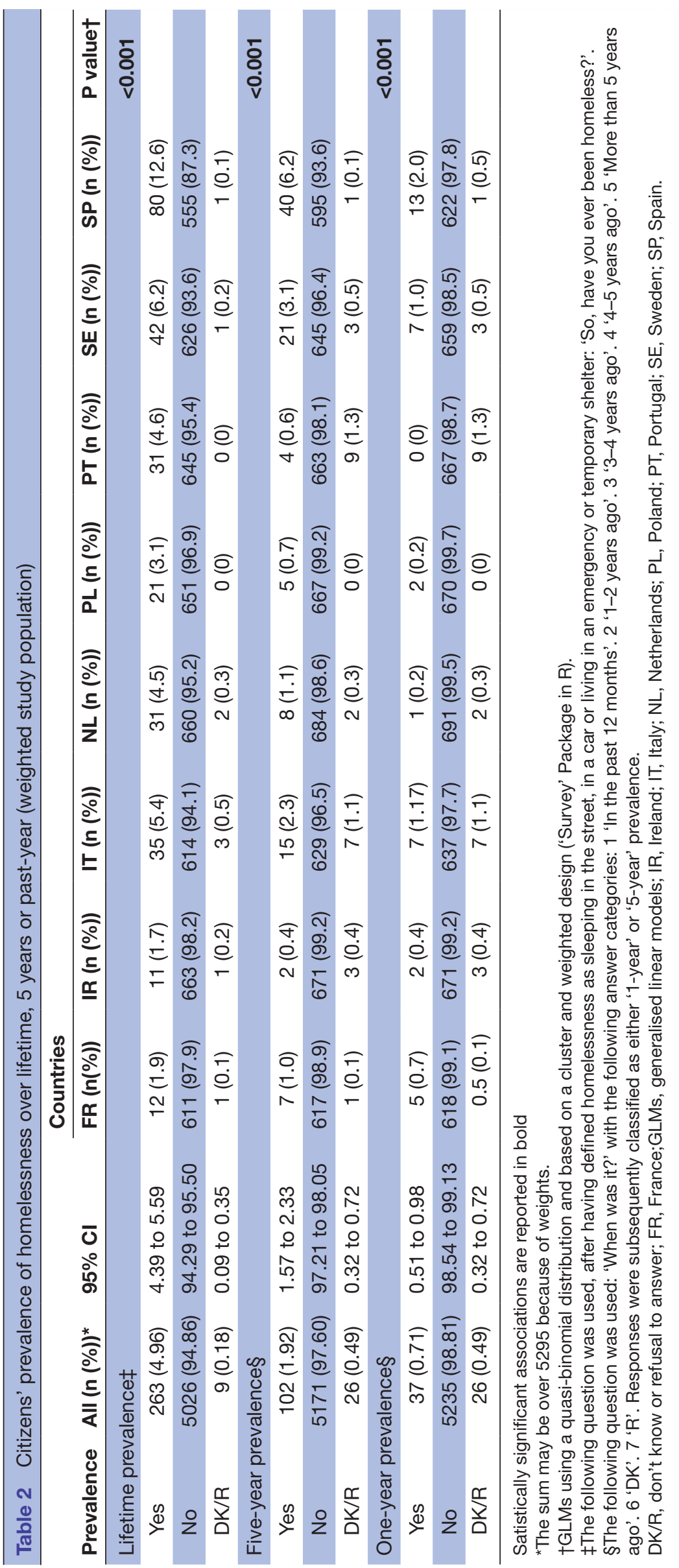


Table 3 Time spent homeless (weighted study population)

\begin{tabular}{|c|c|c|c|c|c|c|c|c|c|c|}
\hline Time spent homeless* & All (n (\%)) & FR (\%) & IR (\%) & IT (\%) & NL (\%) & PL (\%) & PT (\%) & SE (\%) & SP (\%) & $P$ value \\
\hline Periods & & & & & & & & & & $<0.001$ \\
\hline Less than 1 week & $55(20.82)$ & 8.34 & 35.65 & 12.29 & 9.73 & 34.90 & 30.57 & 9.77 & 26.99 & \\
\hline $\begin{array}{l}\text { Less than } 1 \text { year but more } \\
\text { than } 1 \text { month }\end{array}$ & $61(23.25)$ & 6.23 & 9.71 & 3.50 & 41.96 & 20.30 & 8.91 & 39.12 & 27.20 & \\
\hline $\mathrm{DK} / \mathrm{R}$ & 29 (10.95) & 0.00 & 42.25 & 9.16 & 2.12 & 0.00 & 35.94 & 7.57 & 7.33 & \\
\hline
\end{tabular}

*The following question was asked for respondents who reported homelessness 'How much time in total have you been homeless over your life?' with the following answer categories: 1 'Less than a week'. 2 'Less than a month'. 3 'Less than a year'. 4 'Less than 2 years'. 5 'Less than 4 years'. 6 'More than 4 years'. 7 'DK'. 8 'R'.

DK/R, don't know or refusal to answer; FR, France; IR, Ireland; IT, Italy; NL, Netherlands; PL, Poland; PT, Portugal; SE, Sweden; SP, Spain.

ever been homeless were four times as likely to report lifetime homelessness. Age $45-54$ was also significantly associated with increased risk of homelessness. Theseanalyses were repeated to compare respondents with and without past five-year homelessness. Male respondents were 2 times as likely to report 5-yearhomelessness; respondents having relatives, friends, or acquaintances having everbeen homeless were 2.5 times as likely to report 5-year homelessness.

However, these relations cover significant variation between countries. Across all countries, the age group most likely to report experience of homelessness was 45-54 (see table 5). However, in Ireland, Poland and Sweden, the age range with the highest prevalence was 25-34, with very low rates for the 45-54 category in Ireland. Among all countries, men were at a greater risk of experiencing homelessness than women, although in Sweden lifetime prevalence was almost equal between men and women. Although being single also correlated with greater homelessness prevalence, this pattern was reversed in both Ireland and Portugal. Across all countries, prevalence rates dropped along with increased levels of education. However, for France, the Netherlands, Poland, Portugal and Sweden, the most likely group to report homelessness had upper secondary education or vocational training. For Ireland the most at risk group had graduate or postgraduate education, with Sweden's figures also high for this category. No prevalence was reported in either Ireland or Sweden for those with only lower secondary education. Current working status also provided a good prediction of lifetime homelessness prevalence, with those being unemployed (when interviewed) at greater risk. However, data for the Netherlands and Portugal ran counter to this trend, with higher reported prevalence alongside those reporting a working status at the time of interview.

\section{DISCUSSION}

This survey provides one of the first attempts to quantify homelessness prevalence across several European countries, in contrast to existing PIT counts and homeless service use statistics. The results provide a series of important insights about the extent and nature of homelessness prevalence in Europe. The most immediate and evident conclusion that can be drawn from this survey is that homelessness has a far greater impact in the surveyed countries than might be implied by existing measures. For example, existing official data puts Spain and Ireland among the lowest levels of reported homeless at any one point in time, at $0.05 \%$ of the population, with figures across other European counties ranging from $0.1 \%$ to $0.3 \% .^{20}$ Our results present a stark contrast, with homelessness prevalence close to $5 \%$ across the surveyed countries, and the highest rates of homelessness prevalence in Spain at $12.5 \%, 6 \%$ and $2 \%$ for lifetime, 5 -year and past-year prevalence, respectively. Based on our estimates extrapolated across all of Europe, lifetime prevalence of homelessness would encompass 37 million individuals. Similarly, extrapolating past-year prevalence estimates across Europe, our survey suggests that nearly 5.3 million individuals experienced homelessness, far surpassing previous estimates. ${ }^{3}$ As our survey data will almost certainly exclude currently homeless people, the real difference in figures will be much larger.

These results highlight the importance of prevalence studies in comparison to existing methods (PIT and service-user estimates) in order to more effectively assess the extent of homelessness in Europe. The large discrepancies between our prevalence data and official figures relate to at least two issues-first the sampling process itself, using representative phone-based surveys rather than street or shelter counts and other outreach methods. The latter methods are well known to underestimate the number of people experiencing homeless as they will inevitably miss a proportion of the population. Second, prevalence counts assess the number of people experiencing homelessness over time rather than in a single night (or week or month), and therefore, provide a much better estimate of the transient portion of people experiencing homelessness. 


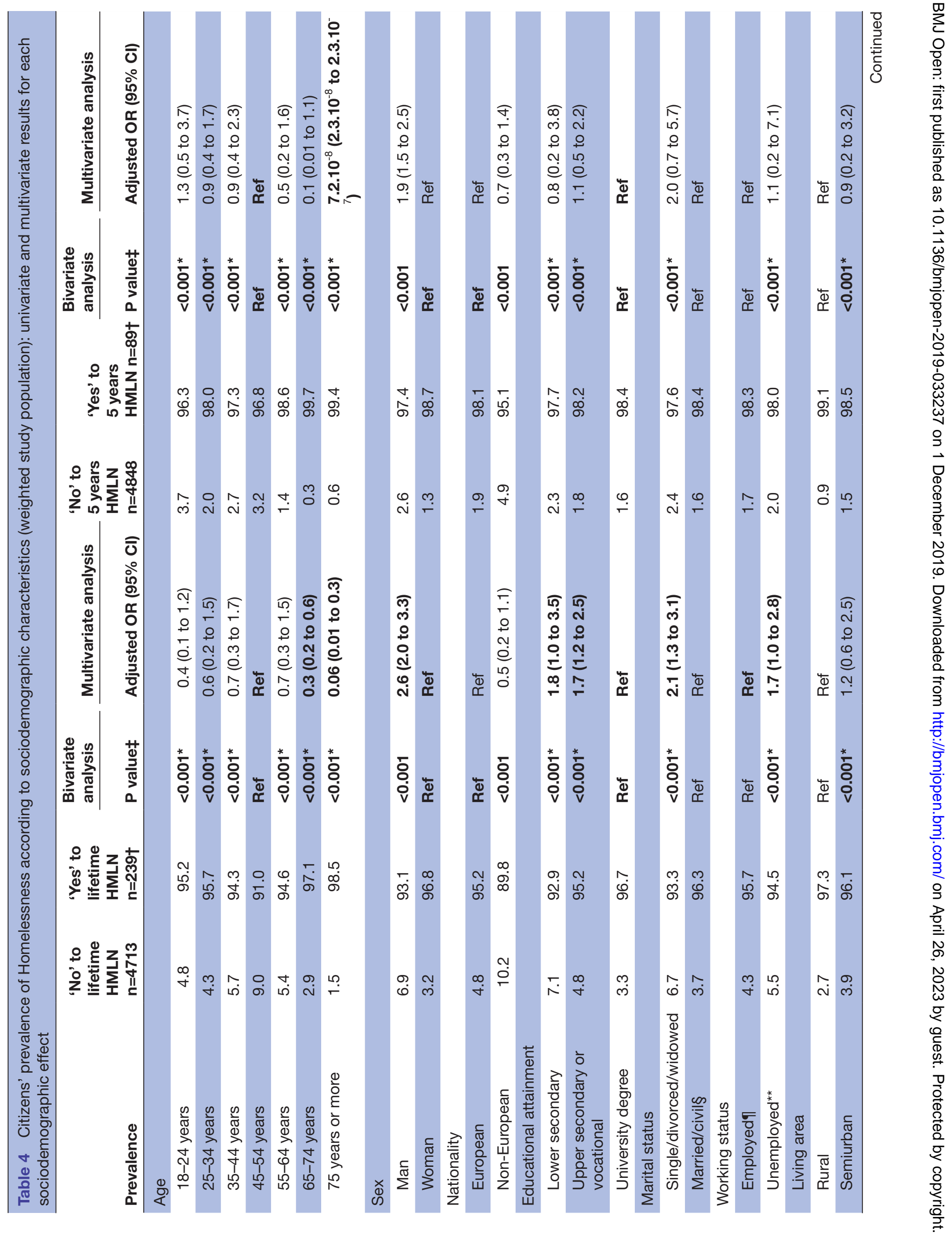




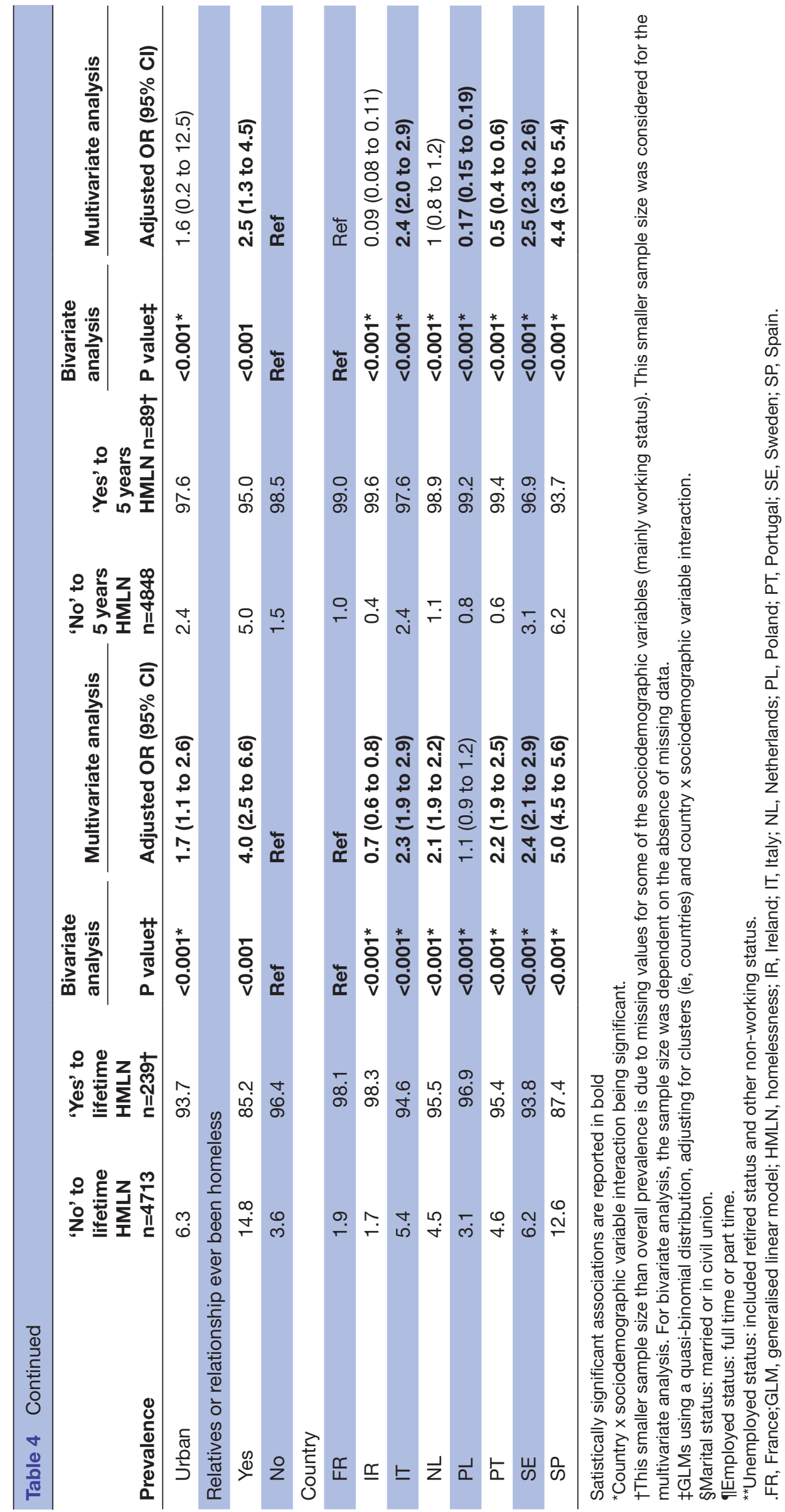


Table 5 Citizens' lifetime prevalence of homelessness by country and by sociodemographic characteristics (weighted study population)

\begin{tabular}{|c|c|c|c|c|c|c|c|c|}
\hline Characteristics & FR (\%) & IR (\%) & IT (\%) & NL (\%) & PL (\%) & PT (\%) & SE (\%) & SP (\%) \\
\hline \multicolumn{9}{|l|}{ Age } \\
\hline 18-24 years & 1.2 & 0.3 & 2.4 & 0 & 0 & 0.9 & 2.2 & 1.7 \\
\hline 25-34 years & 0.4 & 1.2 & 0.4 & 1.6 & 2.3 & 0.7 & 3.3 & 2.1 \\
\hline $35-44$ years & 0.4 & 1.1 & 2.9 & 1.7 & 1.8 & 4.1 & 2.5 & 4.0 \\
\hline $45-54$ years & 1.5 & 0.3 & 2.8 & 3.9 & 1.8 & 1.6 & 3.0 & 16.8 \\
\hline $55-64$ years & 0 & 0.6 & 3.1 & 3.6 & 2.0 & 2.3 & 2.6 & 2.3 \\
\hline $65-74$ years & 0.4 & 0.8 & 1.7 & 1.1 & 0 & 1.0 & 0.7 & 2.6 \\
\hline 75 years or more & 0.7 & 0 & 0 & 0 & 0 & 1.3 & 1.4 & 0.9 \\
\hline \multicolumn{9}{|l|}{ Sex } \\
\hline Man & 3.3 & 3.5 & 10.1 & 7.5 & 5.2 & 8.2 & 8.0 & 21.2 \\
\hline Woman & 1.3 & 0.8 & 3.3 & 4.3 & 2.6 & 3.6 & 7.7 & 9.1 \\
\hline \multicolumn{9}{|l|}{ Educational attainment } \\
\hline Lower secondary & 0.6 & 0 & 7.6 & 3.3 & 1.7 & 4.0 & 0 & 20.2 \\
\hline Upper secondary or vocational & 3.7 & 1.0 & 4.6 & 7.0 & 5.6 & 5.6 & 9.3 & 4.8 \\
\hline University degree & 0.4 & 2.4 & 1.6 & 2.1 & 0.8 & 2.6 & 5.6 & 5.2 \\
\hline \multicolumn{9}{|l|}{ Marital status } \\
\hline Single/divorced/widowed & 3.3 & 1.1 & 8.4 & 7.8 & 4.4 & 4.6 & 9.1 & 19.3 \\
\hline Married/civil ${ }^{\star}$ & 1.3 & 3.1 & 4.9 & 4.1 & 3.5 & 7.2 & 6.6 & 11.0 \\
\hline \multicolumn{9}{|l|}{ Working status } \\
\hline Employed† & 1.0 & 2.6 & 7.0 & 7.5 & 4.3 & 8.2 & 6.2 & 6.8 \\
\hline Unemployed $\neq$ & 3.7 & 1.8 & 6.0 & 4.8 & 3.7 & 3.9 & 8.5 & 24.0 \\
\hline \multicolumn{9}{|l|}{ Living area } \\
\hline Rural & 0 & 0.4 & 0.9 & 2.7 & 0.4 & 0.5 & 4.0 & 2.1 \\
\hline Semiurban & 0.4 & 2.7 & 2.4 & 2.1 & 2.2 & 1.9 & 5.7 & 2.5 \\
\hline Urban & 4.3 & 1.3 & 10.0 & 6.8 & 4.2 & 9.7 & 6.3 & 2.6 \\
\hline
\end{tabular}

In bold: the higher proportion in each country.table 4

*Marital status: married or in civil union.

†Employed status: full time or part time.

fUnemployed status: included retired status and other non-working status.

FR, France; IR, Ireland; IT, Italy; NL, Netherlands; PL, Poland; PT, Portugal; SE, Sweden; SP, Spain.

The results from this survey align with attempts to quantify homelessness prevalence in other countries that have recorded much higher figures than those produced by existing measures. ${ }^{910} 2122$ The average across our surveyed countries is less than recent studies for the USA, which recorded $4.2 \%$ lifetime prevalence of homelessness lasting at least 1 month, ${ }^{10}$ and estimates from Toro et al of $6.1 \%$ for lifetime homelessness as measured in our survey. Our estimates are also similar to limited prior European data available. With an earlier community telephone survey (2001-2005), Toro et al found prevalence rates of $4.0 \%$ for Italy, ${ }^{11}$ with our figure of $5.4 \%$ perhaps accounting for the recorded rise in homelessness in Italy over the past decade. However, as mentioned, existing European data are scarce and the data collection of Toro et al was spread over a significant time period, which makes comparable figures hard to find.
The rate of longer experiences of homelessness reported in Poland, Italy, the Netherlands and Sweden is particularly striking. However, if we account for lifetime prevalence rates as proportions of their populations (Eurostat, 2017) exposed to experiences of homelessness lasting more than a year, Sweden, Italy and Spain have the highest rates with approximately $1.9 \%, 1.6 \%$ and $1.2 \%$, respectively, with the Netherlands around $1 \%$ and Poland at $0.6 \%$. For Italy this is particularly concerning, as with the largest population among these countries, $1.6 \%$ amounts to around 960000 people having experienced homelessness lasting more than a year (with approximately 560000 in Spain and 190000 in Sweden). Bearing this in mind, our data on time spent homeless otherwise support existing estimates of homelessness duration in Italy, which reported $40 \%$ of people experiencing homelessness as having been in the streets for more than 4 
years, ${ }^{23}$ and in Poland where almost a quarter of homeless people are reported to have remained homeless for more than 10 years. ${ }^{24}$ It is notable that these results appear to cut across certain aspects of homelessness policy, as Poland and Italy have only recently begun to formulate national approaches to homelessness, Spain introduced a national strategy in 2015, and Sweden and the Netherlands have had national strategies in place since 2007 and 2006 , respectively. It is certain that the different policy contexts between the different countries in this study will have an effect on the prevalence rates, however, to date the variations and definitions in approach between European states put such an analyses beyond the scope of this study. These connections certainly warrant further research.

At the aggregate level, most of our results confirm previous data on the sociodemographic profile of people at risk of homelessness; namely that higher prevalence rates are found among single men with lower education levels and that prevalence is higher in urban areas. ${ }^{10}$ This does run counter to the first attempts to measure prevalence in the USA using similar methods that found only modest trends for age, gender, marital status and community size. ${ }^{9}$ However, our aggregate data cover a wide degree of variance between the eight European countries, which reveals the experience of homelessness to be a much more varied phenomenon than might be insinuated from previous data, subjective views on national characteristics, or the pooled statistics from this survey.

The relationship between age and homelessness prevalence in our survey is worth noting, although our results for lifetime prevalence do not tell us when someone first experienced homelessness, whether this was a one-off experience, or the frequency and duration any recurrence of homelessness. Despite these limitations, it is possible to discern some pattern to the varying experiences of homelessness. Some surveyed countries (Spain, Portugal and Italy) have very wide experiences of homelessness by age group, whereas for others it is far less dispersed (particularly Poland). Figures for France imply two clusters; much younger people and those in the 45-54 age group. From our data, it is impossible to say whether or not this is a recent phenomenon, possibly linked to the ongoing effects of the latest financial crisis, but it does seem likely that a significant proportion of overall homelessness experience occurs at a younger age. Such higher youth rates could reinforce the relationship between unemployment and homelessness prevalence, considering youth unemployment rates across Europe. ${ }^{25}$ However, recent European data also suggest increasing labour market participation between the ages of $15-24 .^{26}$ The charity Shelter in the UK has noted record rates of in-work homelessness in England, ${ }^{27}$ therefore, it is likely that homelessness prevalence among younger people would also include employed people. Rising rental prices and decreasing real wages are likely to increase the risk of working homelessness for all age groups. ${ }^{28}$
There are other notable exceptions to the general sociodemographic profile that caution against linking homelessness to particular demographics and characteristics. Experience of homelessness by education level reveals that homelessness prevalence ranged from about 1.5 to 2 times greater in the lower education group than in the rest of the population. Nonetheless, Sweden and Ireland stand out as having no reported homelessness alongside only high school education. When coupled with the prevalence of homelessness among the currently employed, our survey results suggest exercising caution in describing homelessness simply as an expression of socially disadvantaged groups in terms of education and employment.

The variance between countries, along with prior US studies like that of Link et al that found differing indicators, suggests that it would be valuable to explore demographic variables further with quantitative and qualitative work. It is likely that the prevalence rates reported here cover a wide range of causal experiences (pathways into and out of homelessness) that vary with general economic forces, gender, ${ }^{29}$ sexual orientation or non-binary identities $^{30}$ and other forms of exposure to discrimination. ${ }^{31}$

\section{Strengths and weaknesses of study}

The major strengths of this study have been discussed above. In addition to these, we can stress that this study included a large sample of adult European citizens, used a relevant probability-weighted approach to ensure the representativeness of the sample, and included an extremely low rate of missing data. All of these strengths provide a strong basis to obtain reliable conclusions. However, the study has some limitations. First, the survey method employed excluded those without a landline or mobile phone. It is certain that the selection bias in this instance will result in an underestimation of homelessness prevalence, as it almost certainly excludes people who are currently homeless, and the demographic living in housing without a landline or mobile phone will tend to represent the poorest section of society. Additionally, in this study, we were not able to collect relative percentages of mobile phone or landline responses, in part due to the repeated call back procedure and respondents' requests to receive a call on a different line leading to mixed data. We are, therefore, not able to report the relative proportions of responses by landline and mobile phone.

It is possible that the stigma of homelessness may have led some respondents to feel reluctant to report homelessness, although the anonymity of the telephone survey procedure is likely to minimise this effect. ${ }^{32}$ In addition, as part of a broader project examining long-term homelessness, the prevalence questions in our survey focused on literal homelessness, as it was necessary to keep the interview as concise as possible. This does, however, restrict the scope of this study to the most visible forms of homelessness. It is also possible that the phrasing of our definition of homelessness referring to sleeping in the street or in a car will create a bias towards urban forms of homelessness. However, we hope this will be mitigated 
by the open discussion of the telephone interview with the possibility for respondents to clarify any doubts with the interviewer.

Some of the survey data for time spent homeless was limited by high refusal rates, particularly for Ireland and Portugal. It is impossible to know if these refusals were due to the particularities of the individual interviewers and/ or particular cultural differences (eg. readily accepting a refusal to answer), or particularly reluctant respondentsalthough it is difficult to imagine a reason to refuse to report the length of homelessness after reporting having been homeless. The stark contrast between these higher rates and the generally extremely low refusal rates for acknowledging homelessness encountered in our survey are intriguing and encourage further study.

There are also some elements to the survey design that limit our interpretation. For example, it is impossible to build a pattern of cumulative periods, individual long periods spent homeless, or the numbers for whom homelessness represents a recurrent or one-off crisis. Our survey was also not able to investigate how periods of homelessness related to unemployment or other forms of social stress. As a result, we were only able to draw inferences between current working status and past homelessness experience.

The correlations between homelessness prevalence and sociodemographics were also limited by two aspects of our dataset. First, our sample size prevented effective GLM analysis of past-year prevalence. For certain sociodemographic data, particularly age, this may induce bias (it is likely that cumulative experience will bias lifetime prevalence toward older age groups). Second, data on ethnicity, sexual orientation and gender identity were not investigated due to legal restrictions on data collection in some of the participating countries, limiting our ability to investigate these well-explored correlates of homelessness. In addition, living area was limited by being defined by the respondents own perception of where they lived, and as a consequence these data are not standardised. For legal reasons, it was not possible for our study to use geocodes or other methods of locating respondents.

Finally our survey targeted European citizens. This means that recent migrants and refugees, two groups that are particularly vulnerable to homelessness, will have been excluded from the survey. This also means we cannot use this survey's data to draw conclusions about the interaction between lifetime prevalence and citizenship or residency status, particularly for those exposed to discrimination. Recent European data demonstrate growing homelessness among migrants in Europe, and studies in the USA have noted higher prevalence among minority populations. ${ }^{31} 33$

\section{Conclusions and policy implications}

Our data show that the scope of homelessness in Europe is far wider than suggested by official statistics. Lifetime $(4.96 \%)$, 5-year $(1.92 \%)$ and past-year $(0.71 \%)$ prevalence rates point towards a serious social problem. The impact of homelessness on health means this also presents a serious concern for public health. Although our survey data encourage a focus on individual and demographic factors, the structural drivers of homelessness undoubtedly continue to play a key role.

The variation between the eight surveyed countries prompts consideration of the different policy approaches that affect the structural drivers of homelessness. Although it is clear that most European countries have experienced similar dynamics of falling real wages alongside significant rises in the cost of living, most significantly in the cost of rental housing, this has not produced a uniform homelessness crisis. Overall the prevalence across Europe demonstrates the need for new and innovative social policy designed to help those who experience homelessness, as well as to help prevent people from falling into such dire circumstances. This is particularly important for broader issues of public health.

\section{Author affiliations}

${ }^{1}$ School of Medicine - La Timone Medical Campus, EA 3279: CEReSS, Aix-Marseille Universite, Marseille, France

${ }^{2}$ Department of Clinical Research and Innovation, Support Unit for Clinical Research and Economic Evaluation, APHM, Marseille, France

${ }^{3} \mathrm{APPsyCl}$ - Applied Psychology Research Center: Capabilities and Inclusion, Instituto Superior de Psicologia Aplicada, Lisboa, Lisboa, Portugal

${ }^{4}$ FEANTSA - European Federation of National Organisations Working with the Homeless, Brussels, Belgium

${ }^{5}$ Department of Psychology, University of Limerick, Limerick, Ireland

${ }^{6}$ Department of Developmental and Social Psychology, University of Padova School of Psychology, Padova, Veneto, Italy

${ }^{7}$ Impuls - Netherlands Center for Social Care Research, Department of Primary and Community Care, Radboud University Medical Center, Nijmegen, The Netherlands

${ }^{8}$ Institute of Psychology, Opole University, Opole, Poland

${ }^{9}$ Rais Fundación, Madrid, Spain

${ }^{10}$ Stockholm Center for Psychiatry Research and Education, Karolinska Institute, Stockholm, Stockholm County, Sweden

${ }^{11}$ Department of Psychology, Wayne State University, Detroit, Michigan, USA

Acknowledgements The authors would like to thank all interviewers who contributed to data collection and M2Consultant firm for its work monitoring the procedures for the telephone survey.

Collaborators Members of the HOME_EU (Horizon 2020 GA/726997) Consortium Study Group: Maria J.Vargas-Moniz, Maria F Jorge-Monteiro, (APPsyCl - Applied Psychology Research Center Capabilities and Inclusion, ISPA-Instituto Universitário, Rua Jardim do Tabaco, 34, 1149-041 Lisboa, Portugal); Ronni M. Greenwood, Rachel M. Manning, Branagh 0'Shaughnessy (Department of Psychology, University of Limerick, Limerick, V94 T9PX, Ireland); Inês Almas, Teresa Duarte (AEIPS-The Association for Study and Psychosocial Integration; Housing First project: Casas Primeiro, Av. António José de Almeida, 26, 1000-043 Lisboa, Portugal); Francesca Disperati, Marta Gaboardi, Michela Lenzi, Massimo Santinello, Alessio Vieno (Department of Developmental and Social Psychology, University of Padova, Via Venezia, 8 -35131 Padova, Italy); Rita P. Marques, Maria Carmona, Américo Nave (Crescer-Community Intervention Association, Bairro Qta Cabrinha 3-E/F 1300-906 Lisboa, Portugal); Freek Spinnewijn (FEANTSA, European Federation of National Organisations Working with the Homeless, Chausse de Louvain 194 Bruxelles 1210, Belgique); Roberto Bernad, Borja Rivero, Martin Julián (Rais Fundación, C/ Ardemans 42, 28028 Madrid, Spain); Anna Bokszczanin, Barbara ZmaczynskaWitek, Skałacka Katarzyna, Aleksandra Rogowska (Institute of Psychology, Opole University, PI. Staszica 1, 45-052 Opole, Poland); Sandra Schel, Yvonne Peters, Tessa van Loenen, Liselotte Raben, Judith R. Wolf (Radboud university medical center, Radboud Institute for Health Sciences, Impuls - Netherlands Center for Social Care Research, Geert Grooteplein 27, 6525 EZ Nijmegen, The Netherlands); Ulla Beijer, Mats Blid, Hakan Kallmen (STAD, Stockholm Center for Psychiatry Research and Education, Karolinska Institutet, Norra Stationsgatan 69, 11364 Stockholm, Sweden); Teresa Bispo, Tiago Cruz, Carla Pereira, (Câmara Municipal 
de Lisboa [The Lisboa City Council], Praça do Município 38, 1100-038 Lisboa, Portugal); Pascal Auquier, Junie M. Petit, Owen Taylor (Aix-Marseille Univ, School of medicine-La timone Medical Campus, EA3279 CEReSS-Health Service Research and Quality of Life Center, 27 Boulevard Jean Moulin, 13385 Marseille, France), Sandrine Loubière, Aurélie Tinland (Department of Research and Innovation, Support Unit for clinical research and economic evaluation, Assistance Publique-Hôpitaux de Marseille, 27 Boulevard Jean Moulin, 13385 Marseille, France).

Contributors OT: Formal analysis (Equal), Investigation (Equal), Methodology (Supporting), Writing-original draft (Lead), Writing-review and editing (Lead). SL: Conceptualisation (Equal), Data curation (Equal), Formal analysis (Lead), Funding acquisition (Supporting), Investigation (Equal), Methodology (Equal), Software (Lead), Validation (Equal), Visualisation (Equal), Writing-original draft (Supporting), Writing-review and editing (Equal). AT: Formal analysis (Supporting), Investigation (Supporting), Methodology (Supporting), Writing-review and editing (Supporting). MV-M: Conceptualisation (Supporting), Funding acquisition (Equal), Writing-review and editing (Supporting). FS: Writing-review \& editing (Supporting). RM: Writingreview and editing (Supporting). MG: Writing-review \& editing (Supporting). JRLMW: Writing-review and editing (Supporting). AB: Writing-review and editing (Supporting). RB: Writing-review and editing (Supporting). HK: Writing-review and editing (Supporting). PT: Writing-review and editing (Supporting). J0: Funding acquisition (Lead). PA: Conceptualisation (Equal), Funding acquisition (Equal), Methodology (Equal), Project administration (Equal), Writing-review and editing (Equal).

Funding This work was supported by the European Commission through a grant, as part of H2020 research project HOME-EU: Reversing Homelessness in Europe H2020-SC6-REVINEQUAL-2016/ GA726997.

Disclaimer The grant agreement between the European Commission and each research unit involved allows complete liberty and autonomy of researchers in the design of the study; the European Commission will take no part in data collection procedures, analyses, interpretation of the data, or decision to submit results.

Competing interests None declared.

Patient consent for publication Not required.

Provenance and peer review Not commissioned; externally peer reviewed.

Data availability statement Data are available in a public, open access repository.

Open access This is an open access article distributed in accordance with the Creative Commons Attribution Non Commercial (CC BY-NC 4.0) license, which permits others to distribute, remix, adapt, build upon this work non-commercially, and license their derivative works on different terms, provided the original work is properly cited, appropriate credit is given, any changes made indicated, and the use is non-commercial. See: http://creativecommons.org/licenses/by-nc/4.0/.

\section{ORCID iDs}

Owen Taylor http://orcid.org/0000-0003-4510-0577

Sandrine Loubiere http://orcid.org/0000-0001-6715-1223

\section{REFERENCES}

1 Feantsa, The Foundation Abbé Pierre. The third overview of housing exclusion in Europe 2018. Brussels, 2018. Available: https://www. feantsaresearch.org/en/report/2018/03/21/the-second-overview-ofhousing-exclusion-in-europe-2017 [Accessed 15 Aug 2018].

2 The Foundation Abbé Pierre, Feantsa. The second overview of housing exclusion in Europe 2017. Brussels, 2017. Available: http:// www.feantsa.org/en/report/2017/03/21/the-second-overview-ofhousing-exclusion-in-europe-2017 [Accessed 16 Aug 2017].

3 European Commission. Confronting homelessness in the European Union. social investment package. Commission staff working document. SWD (2013) 42 final, 20 February 2013, 2013. Available: http://aei.pitt.edu/45917/ [Accessed 4 Aug 2017].

4 Beijer U, Wolf A, Fazel S. Prevalence of tuberculosis, hepatitis C virus, and HIV in homeless people: a systematic review and metaanalysis. Lancet Infect Dis 2012;12:859-70.

5 Oppenheimer SC, Nurius PS, Green S. Homelessness history impacts on health outcomes and economic and risk behavior intermediaries: new insights from population data. Fam Soc 2016;97:230-42.

6 Stuckler D, Reeves A, Loopstra R, et al. Austerity and health: the impact in the UK and Europe. Eur J Public Health 2017;27:18-21.

7 Doherty J, Busch-Geertsema V, Karpuskiene V, et al. Homelessness and exclusion: regulating public space in European cities. Surveill Soc 2002;5.
8 Busch-Geertsema V, Culhane D, Fitzpatrick S. Developing a global framework for conceptualising and measuring homelessness. Habitat Int 2016;55:124-32.

9 Link BG, Susser E, Stueve A, et al. Lifetime and five-year prevalence of homelessness in the United States. Am J Public Health 1994;84:1907-12.

10 Tsai J. Lifetime and 1-year prevalence of homelessness in the US population: results from the National epidemiologic survey on alcohol and related Conditions-III. J Public Health 2018;40:65-74.

11 Toro PA, Tompsett CJ, Lombardo S, et al. Homelessness in Europe and the United States: a comparison of prevalence and public opinion. J Soc Issues 2007;63:505-24.

12 Home_EU. Reversing homelessness in Europe. Available: http:// www.home-eu.org/

13 Barlett JE, Kotrlik JW, Higgins CC. Organizational research: determining appropriate sample size in survey research. Inf Technol Learn Perform J 2001;19.

14 Beaton DE, Bombardier C, Guillemin F, et al. Guidelines for the process of cross-cultural adaptation of self-report measures. Spine 2000;25:3186-91.

15 Petit JM, Loubiere S, Vargas-Moniz MJ, et al. Knowledge, attitudes, and practices about homelessness and willingness-to-pay for housing-first across 8 European countries: a survey protocol. Arch Public Health 2018;76:71.

16 Amore K, Baker M, Howden-Chapman P. The ETHOS definition and classification of homelessness: an analysis. Eur $\mathrm{J}$ Homelessness 2011;5.

17 The World Bank. World development indicators. DataBank. Health: population: structure world development indicators, 2017. Available: https://databank.worldbank.org/data/source/world-developmentindicators [Accessed 11 Jan 2019].

18 Eurostat. Database - Eurostat. Eurostat database, 2017. Available: https://ec.europa.eu/eurostat/web/population-demographymigration-projections/data/database [Accessed 11 Jan 2019]

19 R Core Team. R: a language and environment for statistical computing. Vienna, Austria: R Foundation for Statistical Computing, 2013. http://www.R-project.org/

20 Busch-Geertsema V, Benjaminsen L, Hrast MF, et al. Extent and profile of homelessness in European member states : a statistical update, 2014. Available: http://eprints.whiterose.ac.uk/82606/ [Accessed 30 Apr 2019]

21 Chamberlain C, Johnson G. How many Australians have slept rough? Aust J Soc Issues 2015;50:439-56.

22 Hobden K J, Tompsett C, Fales A K, et al. Comparing public opinion towards and prevalence of homelessness in Canada to the United States. Can J Urban Res 2007;16:76-92.

23 FEANTSA. Country Profile - Italy, 2017. Available: https://www. feantsa.org/en/country-profile/2016/10/18/country-profile-italy? bcParent=27 [Accessed 11 Jan 2019].

24 FEANTSA. Country Profile - Poland, 2017. Available: https://www. feantsa.org/en/country-profile/2016/10/19/country-profile-poland? bcParent $=27$ [Accessed 9 Jan 2019].

25 Eurostat. Unemployment statistics. Available: https://ec.europa. eu/eurostat/statistics-explained/index.php?title=Unemployment statistics\#Youth_unemployment_trends [Accessed 13 May 2019].

26 Eurostat. Youth unemployment. Available: https://ec.europa.eu/ eurostat/statistics-explained/index.php/Youth_unemployment [Accessed 13 May 2019].

27 Shelter, England. Over half of homeless families in England are in work, 2018. Available: https://england.shelter.org.uk/media/press releases/articles/over half of homeless families in england are in work,_shock_new_figures_show [Accessed 13 May 2019].

28 European Commission. Labour market and wage developments in Europe, 2018.

29 Mayock P, Sheridan S, Parker S. 'It's just like we're going around in circles and going back to the same thing ...': the dynamics of women's unresolved homelessness. Hous Stud 2015;30:877-900.

30 Morton MH, Dworsky A, Matjasko JL, et al. Prevalence and correlates of youth homelessness in the United States. J Adolesc Health 2018;62:14-21.

31 Fusaro VA, Levy HG, Shaefer HL. Racial and ethnic disparities in the lifetime prevalence of homelessness in the United States. Demography 2018;55:2119-28.

32 Díaz de Rada V. Face-To-Face versus telephone surveys on political attitudes: a comparative analysis. Qual Quant 2011;45:817-27.

33 Tsai J, Gu X. Homelessness among immigrants in the United States: rates, correlates, and differences compared with native-born adults. Public Health 2019;168:107-16. 